\title{
Temperature Measurements of Shock-Compressed Deuterium
}

\author{
N.C. Holmes, M. Ross, and W. J. Nellis \\ University of California \\ Lawrence Livermore National Laboratory \\ Livermore, CA 94550
}

November 1994

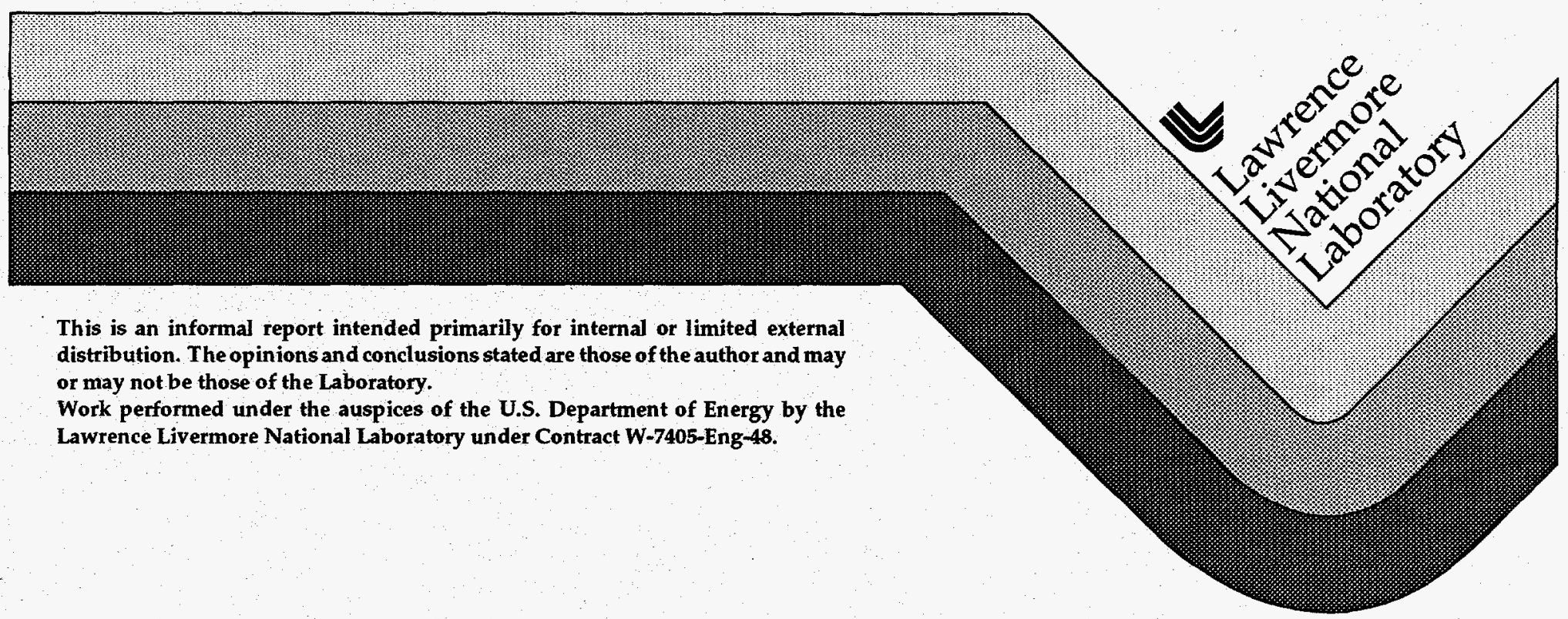




\section{DISCLAIMER}

This document was prepared as an account of work sponsored by an agency of the United States Government. Neither the United States Government nor the University of California nor any of their employees, makes any warranty, express or implied, or assumes any legal liability or responsibility for the accuracy, completeness, or usefulness of any information, apparatus, product, or process disclosed, or represents that its use would not infringe privately owned rights. Reference herein to any specific commercial product, process, or service by trade name, trademark, manufacturer, or otherwise, does not necessarily constitute or imply its endorsement, recommendation, or favoring by the United States Government or the University of California. The views and opinions of authors expressed herein do not necessarily state or reflect those of the United States Government or the University of California, and shall not be used for advertising or product endorsement purposes.

This report has been reproduced directly from the best available copy.

Available to DOE and DOE contractors from the Office of Scientific and Technical Information

P.O. Box 62, Oak Ridge, TN 37831

Prices available from (615) 576-8401, FTS 626-8401

Available to the public from the

National Technical Information Service

U.S. Department of Commerce

5285 Port Royal Rd.

Springfield, VA 22161 


\section{DISCLAIMER}

Portions of this document may be illegible in electronic image products. Images are produced from the best available original document. 


\title{
Temperature Measurements of Shock-Compressed Deuterium
}

\author{
N. C. Holmes, M. Ross, and W.J. Nellis
}

\begin{abstract}
We measured the temperatures of single- and double-shocked $\mathrm{D}_{2}$ and $\mathrm{H}_{2}$ up to $85 \mathrm{GPa}$ $(0.85 \mathrm{Mbar})$ and $5200 \mathrm{~K}$ While single shock temperatures, at pressures to $23 \mathrm{GPa}$, àgree well with previous models, the double shock temperatures are as much as $40 \%$ lower than predicted. This is believed to be caused by molecular dissociation, and a new model of the hydrogen EOS at extreme conditions has been developed which correctly predicts our observations. These data and model have important implications for programs which use condensed-phase hydrogen in implosion systems.
\end{abstract}

Temperature measurements of shock compressed materials provide a very sensitive constraint to theoretical models of the equation of state. This is particulary true for those materials in which shock energy can be absorbed in internal degrees of freedom. In the case of liquid nitrogen, shock temperature measurments showed that dissociation resulted in the phenomenon of "shock cooling." [1] In a series of recent experiments, we measured the temperatures of shock-compressed $\mathrm{D}_{2}$ and $\mathrm{H}_{2}$, and the results have led to a revision in models of hydrogen at high pressure and temperature.

We performed single and double-shock experiments, in which we measured the temperature during the passage of a strong shock in the fluid, and after reflection of the shock off a transparent window. Most of the measurements were in (initially liquid) $\mathrm{D}_{2}$, since its use allows higher pressures and temperatures to be obtained than with $\mathrm{H}_{2}$. Details of the experimental setup can be found in Refs. 2 ( $\mathrm{D}_{2}$ EOS and cryogenic methods) and 3 (optical pyrometer), and the details of this work, its analysis, and the new theoretical model are found in Ref. 4.

The large two-stage light-gas gun in B. 341 was used to generate the shock waves, using projectile velocities up to $7.2 \mathrm{~km} / \mathrm{s}$. The hydrogen samples were condensed

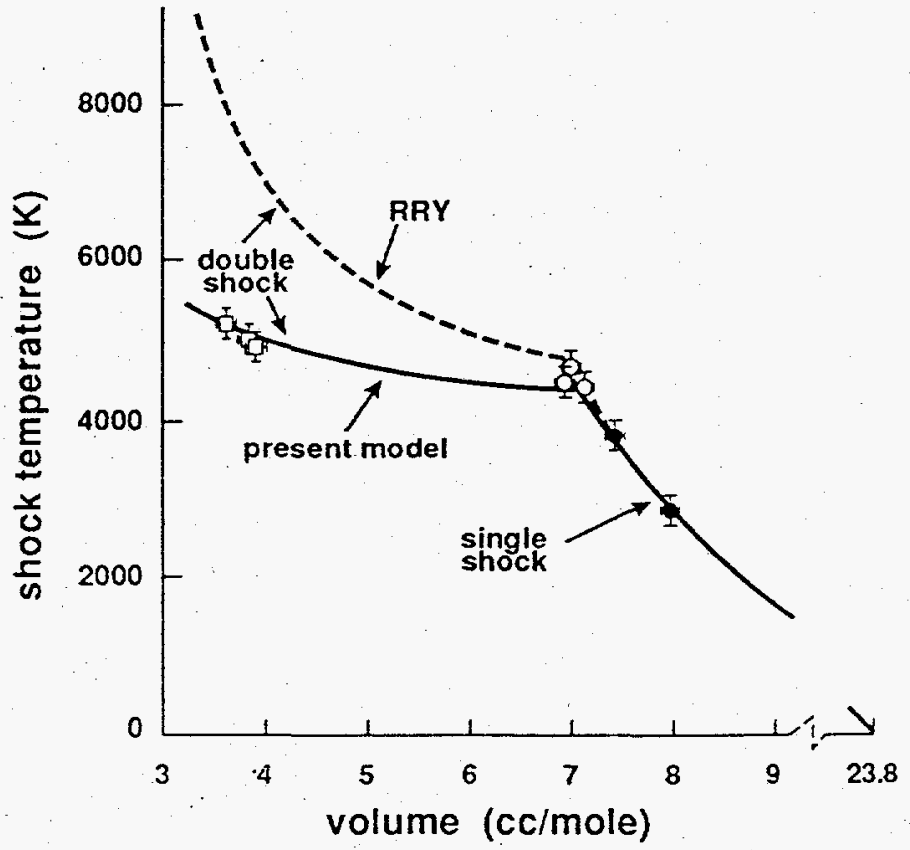

Fig. 1. Comparison of previous theoretical model for $D_{2}$ by Ross, Ree, and Young [5], denoted by RRY, with the present model. Circles refer to single shock states, squares to double shocks. The sets of open circles and open squares are for pairs of single and double shock measurements. 
from research-grade gas into a sample cavity $1.5 \mathrm{~mm}$ thick surrounded by liquid $\mathrm{H}_{2}$ at $20 \mathrm{~K}$ [2] The experiments were planar and one-dimensional in the observation region. We observed the shock temperatures using a fiber-optic-coupled optical pyrometer with an effective sensitivity of $\mathrm{f} / 2.5$ and $\mathrm{I}$ ns time resolution. [3] The sample cavity was bounded on the impact side by an $\mathrm{Al}$ plate, on the other by transparent $\mathrm{Al}_{2} \mathrm{O}_{3}$ or $\mathrm{LiF}$ windows. These windows remain transparent under the conditions of shock loading in our experiments. The results of our experiments on $\mathrm{D}_{2}$ are plotted in in Fig. 1.

The new model developed by Ross, [4] indicated in the figure as the "present model," assumes that the properties of the shocked fluid can be accurately expressed as a mixture of pure phases: molecular and monatomic hydrogen. This model leads to a thermodynamically selfconsistent effective density- and temperature-dependent dissociation energy for calculating the fraction of dissociated molecules. Since the value of this dissociation energy decreases as the the hydrogen is compressed, we predict that hydrogen undergoes a continuous dissociative phase transition in the region of our experiments. The agreement between calculated and measured temperatures, shown in Fig. 1, is remarkably good. This provides us with confidence in the predictive ability of our model. In Figure 2, we compare the principal Hugoniot calculated with the present model (solid line), the old (RRY) model,[5] and to various tabular

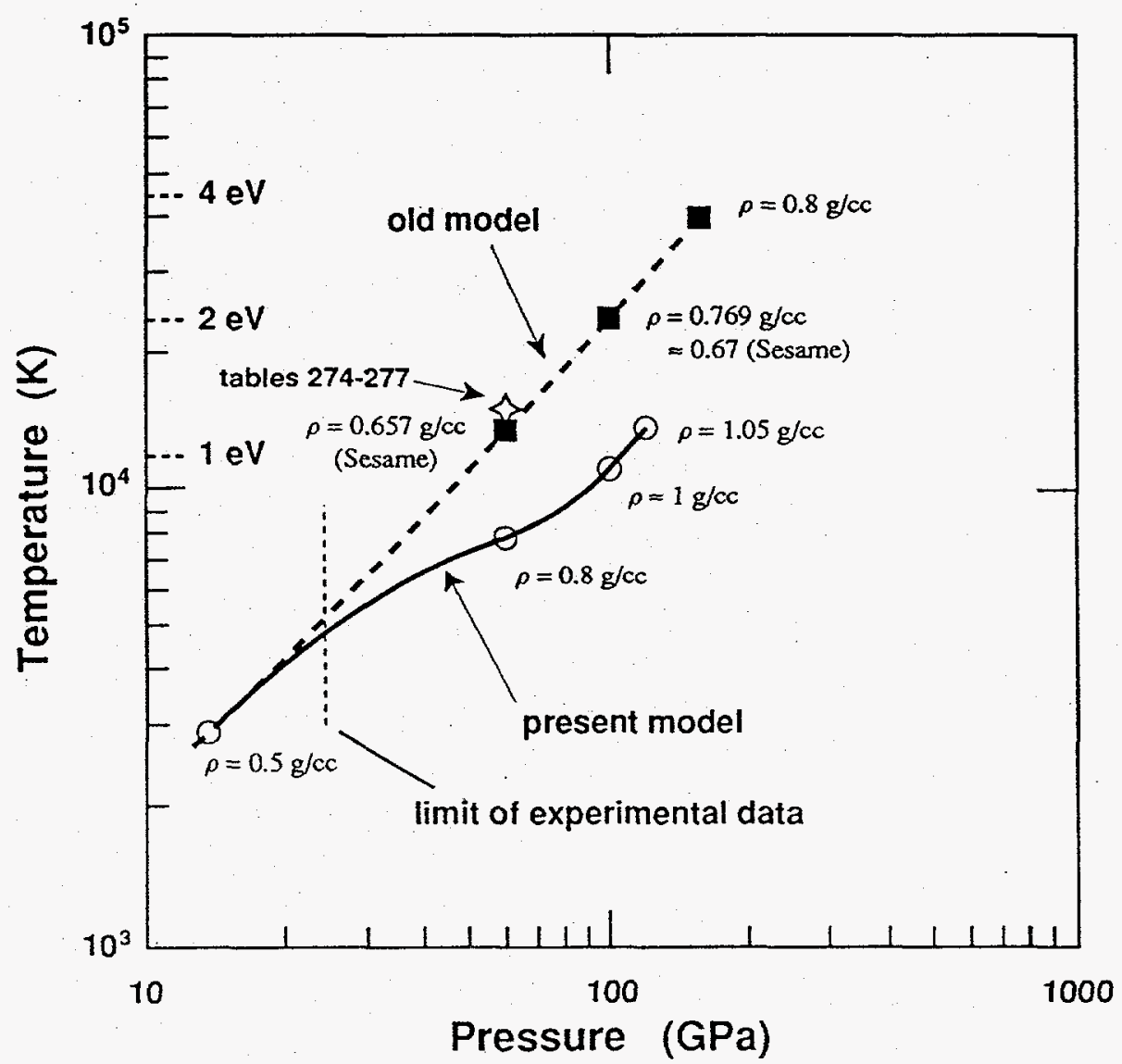

Fig. 2. A calculation of the temperature along the principal Hugoniot of liquid $\mathrm{D}_{2}$ as a function of pressure with the present model (solid curve), with the old model (dashed curve), and tabular equations of state. Representative densities along each locus of states are indicated by open circles and squares for the present and old models, respectively. 
equations-of-state now in use. The tabular data is essentially the same as the old model. On the Hugoniot, we can expect more compression and lower temperatures than previously believed. This is good news!

It is clear from Figure 2 that these calculations are a significant extrapolation beyond our current data set. Higher initial pressures are possible using our gun, up to nearly $30 \mathrm{GPa}$ single shock, $140 \mathrm{GPa}$ in double shocks. We plan to perform experiments to measure the single-and double-shock EOS, and then the shock temperatures at this pressure in the future, to further test and refine the present model.

\section{References}

1. H.B. Radousky, W.J. Nellis, M. Ross, D.C. Hamilton, and A.C. Mitchell, Phys. Rev. Lett. 57, 2419(1986).

2. W.J. Nellis, A.C. Mitchell, M. van Thiel, G.J. Devine, R.J. Trainor, and N. Brown, J. Chem. Phys. 79, 1480(1983).

3. N. C. Holmes, submitted to Rev. Sci. Instrum.

4. N. C. Holmes, M. Ross, and W.J. Nellis, submitted to Phys. Rev. B.

5. M. Ross, F.H. Ree, and D.A. Young, J. Chem. Phys. 79, 1487(1983). 